\title{
O Uso de Artemia sp. como Organismo-Teste para Avaliação da Toxicidade das Águas Residuárias do Beneficiamento da Castanha de Caju Antes e Após Tratamento em Reator Biológico Experimental
}

\author{
M. F. Pimentel ${ }^{1 *}$, F. C. G. Silva Júnior ${ }^{2}$, S. T. Santaella² \& L. V. C. Lotufo ${ }^{1}$ \\ ${ }^{1}$ Laboratório de Ecotoxicologia Marinha, Instituto de Ciências do Mar, Universidade Federal do Ceará - UFC, \\ Av. Abolição, 3207, Fortaleza - CE, Brasil \\ ${ }^{2}$ Laboratório de Efluentes e Qualidade de Água, Instituto de Ciências do Mar, Universidade Federal do Ceará - UFC, \\ CEP 60125-120, Fortaleza - CE, Brasil
}

(Received June 18, 2010; Accepted October 18, 2010)

\begin{abstract}
RESUMO
No Ceará, a castanha está entre os principais produtos de exportação, produzindo durante seu beneficiamento, quantidades significativas de águas residuárias. $\mathrm{O}$ objetivo deste trabalho foi avaliar a remoção da carga tóxica das águas residuárias de uma indústria de castanha de caju após tratamento em um reator aeróbio experimental inoculado com fungos, por meio do teste agudo com o microcrustáceo Artemia sp. e dos níveis de fenóis totais e DQO. Os resultados mostraram que o afluente foi altamente tóxico com elevados níveis de $\mathrm{DQO}$ e fenóis. Além disso, o tratamento biológico melhorou todos os parâmetros analisados. A mortalidade foi reduzida de $84,7 \pm 29,3 \%$ no afluente para $16,3 \pm 25,6 \%$ no efluente. A remoção de fenóis totais chegou a $98,1 \%$, enquanto que as taxas de remoção de DQO alcançaram um valor máximo de $95,8 \%$. Os três parâmetros apresentaram forte correlação positiva. Deste modo, pode-se concluir que o teste de toxicidade aguda com Artemia sp. constitui uma importante ferramenta de monitoramento da eficiência de reatores biológicos utilizados no tratamento de efluentes ricos em fenóis e, além disso, que o tratamento biológico mostrou-se bastante eficaz na melhora da qualidade ambiental de águas residuárias do beneficiamento da castanha de caju.
\end{abstract}

Palavras-chave: Artemia sp., tratamento de efluentes, castanha de caju.

\section{ABSTRACT \\ The Use of Artemia sp. as a Test-Organism to Assess the Toxicity of the Cashew Nut Improvement Industry Effluent Before and After the Treatment by an Experimental Biological Reactor}

The cashew nut is among the most important products of exportation for the State of Ceará, generating considerable amounts of contaminated wastewater. In this context, the aim of this research was to evaluate the efficiency of a biological reactor inoculated with funghi in the treatment of cashew nut industry wastewater using as end-points: the acute toxicity to the microcrustacean Artemia sp., Total Phenol Content (TPC) and Chemical Oxygen Demand (COD). Results showed that the plant effluent is highly toxic, presenting elevated levels of TPC and COD. In addition, it was demonstrated the efficacy of the biological treatment. The mortality was reduced from $84.7 \pm 29.3 \%$ to $16.3 \pm 25.6 \%$. The reduction of TPC reached a maximum of $98.1 \%$, while the reduction for COD levels reached $95.8 \%$. There was a strong positive correlation between toxicity, TPC and COD. It was clearly concluded that the acute toxicity test using Artemia sp. is an important tool in the monitoring of biological reactors efficiency in the treatment of phenol enriched effluents. In addition, it was possible to observe that the biological treatment greatly improved the quality of wastewater from the cashew nut industry.

Keywords: Artemia sp., effluents treatment, cashew nut industry.

* Corresponding author: Marcionília Fernandes Pimentel; e-mail: marcioniliafp@yahoo.com.br. 


\section{INTRODUÇÃO}

A preocupação a respeito dos impactos das atividades humanas em ecossistemas aquáticos tem gerado grande demanda por melhores tecnologias baseadas em detecções rápidas e seguras dos riscos envolvidos. Para Ait-Aissa et al. (2003), tem ficado cada vez mais evidente que análises químicas isoladas não são suficientes para se alcançar boas avaliações de risco em amostras ambientais, pois estas não informam a fração de contaminantes disponível para organismos vivos nem o potencial efeito deles quando misturados. Para que seja obtido um retrato fiel do impacto, é preciso que haja caracterizações ecotoxicológicas integradas às análises químicas (Svensson et al., 2005).

Análises ecotoxicológicas vêm sendo empregadas no monitoramento de efluentes industriais com o intuito de minimizar o impacto ambiental, avaliar a eficiência de estações de tratamento e também como requisito para a obtenção e manutenção de licenças junto aos órgãos ambientais. Esta vertente da toxicologia investiga os efeitos de substâncias químicas manufaturadas e de outros materiais, antropogênicos ou naturais, em organismos aquáticos (Sousa, 2002). Entende-se por toxicidade qualquer efeito adverso manifestado por organismos testes, o que pode incluir desde alterações genéticas, imobilidade, deformidades até letalidade. Vale ressaltar que o uso de testes ecotoxicológicos na avaliação da qualidade de águas e efluentes foi recentemente regulamentado oficialmente, em âmbito federal, por meio da Resolução no .357 de 17 de março de 2005 do Conselho Nacional do Meio Ambiente (CONAMA, 2005).

A produção de castanha de caju destaca-se no cenário industrial como uma das atividades econômicas de maior projeção no nordeste brasileiro. O processamento da castanha (beneficiamento) consiste na retirada da amêndoa de seu interior e, secundariamente, na extração, a partir da casca, do principal subproduto que é o Líquido da Casca da Castanha (LCC), um óleo-resina cáustico presente no mesocarpo esponjoso do fruto (Soares, 1986; Lorenzi \& Matos, 2002). Devido ao constante crescimento desta atividade, este setor industrial tem contribuído significativamente para a poluição de corpos hídricos no estado (Sampaio et al., 2004). Segundo Santaella (1999), neste tipo de indústria, os efluentes são geralmente lançados no ambiente sem nenhum tratamento, e este, quando existe, não atende às condições impostas pela legislação.

Em quase todos os países o tratamento de águas residuárias antes do lançamento é obrigatório. Existem processos de tratamento físico-químico (tratamento eletroquímico, precipitação, oxidação, coagualção-floculação, flotação por ar dissolvido etc.), que são bastante eficientes, porém onerosos e que geram muito lodo, e os processos biológicos (lagoas de estabilização, lodos ativados, reatores anaeróbios etc.) que utilizam microrganismos, principalmente bactérias aeróbias ou anaeróbias, para a degradação da matéria orgânica presente nas águas residuárias. Porém, o que acontece muitas vezes é que os processos físico-químicos convencionais disponíveis não são eficientes para certos tipos de poluente, além de apresentarem custos elevados. Por outro lado, os processos biológicos podem apresentar excelente relação custo/benefício. A degradação biológica de resíduos aquáticos é, geralmente, a mais econômica e eficiente forma de eliminar poluentes (Jou \& Huang, 2003). Neste contexto, sistemas biológicos de tratamento vêm sendo amplamente utilizados ao longo dos últimos anos na biodegradação dos mais diversos tipos de água residuária e com vasta gama de microrganismos (Huwang et al., 2004). Ainda que de forma incipiente, os avanços e descobertas descritos na literatura vêm alcançando, em alguns países, aplicações em escala industrial. Devido à produção de certos metabólitos, os fungos têm atraído grande interesse dos pesquisadores envolvidos em questões ambientais. Atualmente, vários grupos de pesquisa se dedicam a estudos de redução de contaminantes em águas residuárias utilizando fungos.

A busca na literatura por estudos de caracterização e redução da toxicidade em estações de tratamento de efluentes industriais no Brasil revela que ainda há muitas lacunas. Diversos contaminantes de toxicidade desconhecida são lançados diariamente no ambiente apesar de (às vezes) os dados físico-químicos serem bem conhecidos. Portanto, é importante que se comece a obter essas informações nas estações em operação para que seja possível avaliar eventuais impactos que um efluente complexo, de baixa biodegradabilidade, embora tratado, pode causar à biota.

O microcrustáceo Artemia sp. pertence ao filo Arthropoda, classe Crustácea, subclasse Branquiopoda, ordem Anostraca, família Artemidae e Gênero Artemia - Leach, 1819. Possui distribuição cosmopolita e caráter extremamente eurialino. A grande dispersão do gênero pelo mundo em enormes populações pode ser atribuída à reprodução partenogênica com produção de cistos, que ocorre na ausência do macho (Veiga \& Vital, 2002); além disso, os organismos desse gênero atuam como elo trófico entre as comunidades planctônicas e as cadeias superiores.

Por se tratar de um animal de fácil manutenção em condições de laboratório e de ampla distribuição, Artemia sp. tem sido largamente utilizada em testes de toxicidade. O teste com Artemia sp. consiste na exposição dos náuplios na fase II ou III durante 24 e/ou 48 horas a concentrações crescentes da amostra que se pretende testar com análise do número de organismos mortos ao final do período de exposição (Veiga \& Vital, 2002; CETESB, 1987). Apesar da baixa sensibilidade a alguns agentes químicos, o teste de toxicidade aguda mostrou-se extremamente sensível a águas residuárias ricas em compostos fenólicos incluindo àquelas resultantes do beneficiamento da castanha de caju (Guerra, 2001; Campos et al., 2002; Aggelis et al., 2003; Pimentel et al., 2009). Ainda que os testes de toxicidade com efluentes sejam comumente realizados com organismos dulcícolas, o uso de Artemia sp. justifica-se pelo fato de que a maioria dos compostos nocivos despejados têm o ambiente salino como destino final, mesmo quando não são lançados diretamente ao mar.

Neste trabalho foi utilizado o teste agudo com o microcrustáceo Artemia sp. para monitoramento da remoção da carga tóxica dos efluentes de uma indústria de beneficiamento de castanha de caju tratados em um reator aeróbio experimental inoculado com fungos. Foram avaliados, também, os níveis de fenóis totais e DQO. 


\section{MATERIAL E MÉTODOS}

\section{Agua residuária}

A água residuária utilizada neste trabalho foi coletada em uma indústria de beneficiamento de castanha de caju localizada no município de Fortaleza, Estado do Ceará.

\section{Reator aeróbio}

O reator aeróbio foi montado a partir de um cilindro de acrílico com volume total de 3,6 L. Foram inseridos dois pontos de aeração (realizada por mini-compressores de ar), bem como dois ductos (entrada abaixo e saída acima) ligados a uma bomba peristáltica. $\mathrm{O}$ espaço interno foi preenchido com cubos de espuma de poliuretano. O Tempo de Detenção Hidráulica (TDH) adotado foi de 12 horas e a vazão ajustada para 0,24 L.horas ${ }^{-1}$. Os esporos da espécie fúngica Aspergillus niger utilizados como organismos tratadores neste trabalho foram previamente isolados da própria água residuária da indústria onde foram realizadas as coletas. O reator aeróbio de leito fixo e escoamento ascendente foi operado com homogeneização diária do afluente e monitoramentos de vazão durante 215 dias.

A concentração de fenóis totais foi determinada pelo método da extração em clorofórmio e a Demanda Química de Oxigênio (DQO) pelo método colorimétrico de refluxo fechado, seguindo os protocolos descritos por APHA (2005). As variáveis foram determinadas em duplicata, semanalmente e sempre no mesmo dia.

\section{Teste de toxicidade}

O teste de toxicidade aguda com Artemia sp. seguiu o método descrito por Veiga \& Vital (2002) com algumas modificações (Pimentel et al., 2009). Foram realizados seis testes com a substância de referência dodecil sulfato de sódio (SDS) para avaliação da sensibilidade dos náuplios utilizados no trabalho.

Partindo-se de experimentos piloto e efetuados os ajustes necessários, as dez concentrações definitivas testadas com as amostras brutas (afluente) variaram entre as seguintes: 0,007 ; 0,$015 ; 0,03 ; 0,06 ; 0,12 ; 0,25 ; 0,5 ; 1 ; 2 ; 4 ; 8$; e $16 \%$. Com as amostras de efluente do reator as concentrações testadas foram: $2 ; 4 ; 8 ; 16 ; 32 ; 64$ e $80 \%$. Todos os experimentos foram executados partindo-se da amostra bruta diluída em água do mar captada em zona oceânica e filtrada em membrana de $0,45 \mu \mathrm{m}$ que funcionou, também, como controle negativo. Não houve salinização em nenhuma das concentrações. Os experimentos foram realizados em placas estéreis de 24 cavidades sendo adicionados 10 náuplios em cada cavidade. A placa foi preparada com três réplicas por concentração sendo o volume final de $2,5 \mathrm{~mL}$ cada. Após os períodos de 24 e de 48 horas foi realizada a contagem (em lupa) dos organismos mortos em cada réplica. As placas foram incubadas a $25^{\circ} \mathrm{C}$ durante 48 horas.

\section{Determinações físico-químicas}

Paralelamente a cada teste foram medidos $\mathrm{pH}$, Oxigênio dissolvido e salinidade na água de diluição e na maior concentração testada.

\section{Análise estatística}

Seguindo a contagem dos organismos mortos, foi efetuado o cálculo da concentração que causou a morte de $50 \%$ dos organismos testados $\left(\mathrm{CL}_{50}\right)$ por meio do método Trimmed Spearman-Karber (Hamilton et al., 1977), assim como o seu intervalo de confiança (IC 95\%). Pelo fato de não ter sido possível detectar a $\mathrm{CL}_{50} \mathrm{em}$ muitos dos testes, devido à mesma ter estado além dos limites das concentrações testadas, optou-se por utilizar, nas comparações estatísticas, a mortalidade em uma das concentrações comum a todos os testes em todas as amostras (4\%). As médias das $\mathrm{CL}_{50}$ das duas amostras (afluente e efluente) obtidas após 24 e 48 horas de exposição, bem como a mortalidade na concentração de $4 \%$, foram comparadas pelo teste t' de Student pareado com um nível de significância de 5\%. Já na comparação das médias obtidas para amostras diferentes após o mesmo período de exposição foi utilizado o teste t' de Student não pareado. Todas as análises foram realizadas no programa GraphPad Prism versão 4.02 (GraphPad Software, Inc).

A ocorrência de correlação entre toxicidade, $\mathrm{DQO}$ e fenóis foi avaliada pelo teste de Spearman, considerando um $p$ menor que 0,05 utilizando o programa STATISTICA versão 6.0.

As médias e porcentagem de remoção nas análises de fenóis totais e DQO foram calculadas por meio do programa EXCEL versão 2003.

\section{RESULTADOS}

O reator foi operado durante 215 dias e, durante todo este período, a toxicidade tanto do afluente quanto do efluente foi monitorada por meio do teste agudo com Artemia sp. As coletas e análises de toxicidade bem como de fenóis totais e DQO foram realizadas semanalmente.

\section{Toxicidade}

A partir dos seis ensaios realizados com o SDS (substância de referência), obteve-se $\mathrm{CL}_{50}$ média de 24,78 $\pm 2,23 \mathrm{mg} . \mathrm{L}^{-1}$, estando esta devidamente contida na faixa entre 13,1 e 30,9 mg.L $\mathrm{L}^{-1}$ em 24 horas, estabelecida pelo protocolo seguido para este trabalho (Veiga \& Vital, 2002; Pimentel et al., 2009).

Com relação ao afluente do reator, as variáveis físicoquímicas (monitoradas a cada teste na concentração mais alta $-16 \%$ ), apresentaram os seguintes resultados: salinidade média de 34,9 ( $\mathrm{DP}=1,73)$; nível de oxigênio dissolvido de $6,2 \mathrm{mg} \cdot \mathrm{L}^{-1}(\mathrm{DP}=1,16)$ e $\mathrm{pH}$ médio de $6,9(\mathrm{DP}=0,58)$.

Todas as dezessete amostras testadas do afluente foram tóxicas a Artemia sp. Os resultados dos experimentos de toxicidade podem ser observados na Tabela 1, na qual estão expostos os valores de $\mathrm{CL}_{50}$ bem como a mortalidade na concentração $4 \%$. Os valores das $\mathrm{CL}_{50}$ variaram de 0,07 a $14,8 \%$ no período de 24 horas, enquanto no período de 48 horas a variação foi de 0,02 a $11,9 \%$. No período de 24 horas, a mortalidade em $4 \%$ foi de $70,2 \pm 38,4 \%$, enquanto em 48 horas a média foi de $84,7 \pm 29,3 \%$. A comparação entre os valores de $\mathrm{CL}_{50}$ e da mortalidade em $4 \%$ após 24 e 48 horas de incubação revelou diferenças significativas entre os dois períodos de exposição $(\mathrm{p}<0,05)$, indicando um ligeiro aumento de toxicidade com aumento do tempo incubação. 
No que diz respeito ao efluente, foram medidas as variáveis físico-químicas na diluição mais alta $(80 \%)$ e estas apresentaram os seguintes valores: salinidade média de 9,4 $(\mathrm{DP}=1,16)$, nível de oxigênio dissolvido igual a $6,1 \mathrm{mg} \cdot \mathrm{L}^{-1}$ $(\mathrm{DP}=2,83)$ e $\mathrm{pH}$ médio de $6,8(\mathrm{DP}=0,63)$.

Os resultados dos experimentos de toxicidade com amostras do efluente (Tabela 2) foram bastante diferentes dos encontrados nas análises com o afluente, com valores médios de $\mathrm{CL}_{50}$ variando entre $38,14 \pm 11,2 \%$ e $42,26 \pm 8,3 \%$ para 24 e 48 horas de incubação, respectivamente. $\mathrm{A} \mathrm{CL}_{50}$ mínima calculada foi $4,45 \%$ e a máxima de $77,49 \%$ em 24 horas. Para o período de 48 horas a $\mathrm{CL}_{50}$ variou de 6,82 a $79,55 \%$. Dos 30 náuplios expostos à diluição de $4 \%$ do efluente, a mortalidade foi de $4,3 \pm 10,8 \%$ em 24 horas e $16,3 \pm 25,6 \%$ em 48 horas. A comparação entre os valores de $\mathrm{CL}_{50}$ e a mortalidade em $4 \%$ após 24 e 48 horas de incubação com o efluente revelou diferenças significativas $(\mathrm{p}<0,05)$.

Quando comparados os valores obtidos $\left(\mathrm{CL}_{50}\right.$ e mortalidade) do afluente e efluente do reator, foram observadas diferenças significativas para ambos os tempos de incubação $(p<0,05)$, ressaltando a redução de toxicidade executada pelo tratamento biológico. Sendo assim, os valores de $\mathrm{CL}_{50}$ foram significativamente

Tabela 1 - Valores de $\mathrm{CL}_{50}$ com os limites de confiança e número de organismos mortos em 4\% do AFLUENTE, seguidos da média e erro padrão da média e coeficiente de variação.

\begin{tabular}{|c|c|c|c|c|c|c|}
\hline \multirow{2}{*}{$\begin{array}{l}\text { Afluente } \\
\text { Coletas }\end{array}$} & \multicolumn{3}{|c|}{24 horas } & \multicolumn{3}{|c|}{48 horas } \\
\hline & $\mathrm{CL}_{50}(\%)$ & Limite de confiança & Mortalidade (\%) & $\mathrm{CL}_{50}(\%)$ & Limite de confiança & Mortalidade (\%) \\
\hline 2 & 0,19 & $0,09-0,41$ & 93,3 & $*<0,06$ & - & 100 \\
\hline 3 & 0,64 & $0,48-0,85$ & 93,3 & ${ }^{*}<0,06$ & - & 100 \\
\hline 4 & $\star<0,03$ & - & 100 & $\star<0,03$ & - & 100 \\
\hline 5 & 0,18 & $0,13-0,25$ & 100 & ${ }^{*}<0,03$ & - & 100 \\
\hline 6 & 0,13 & $0,09-0,17$ & 100 & $*<0,03$ & - & 100 \\
\hline 7 & 0,16 & $0,13-0,20$ & 100 & ${ }^{*}<0,007$ & - & 100 \\
\hline 9 & 3,17 & $2,77-3,64$ & 70 & 1,16 & $0,94-1,43$ & 96,6 \\
\hline 10 & 0,07 & $0,06-0,09$ & 100 & 0,02 & $0,02-0,02$ & 100 \\
\hline 13 & 1,41 & $1,18-1,69$ & 93,3 & 0,57 & $0,45-0,51$ & 100 \\
\hline 14 & 1,15 & $0,94-1,39$ & 100 & 0,18 & $0,14-0,23$ & 100 \\
\hline 15 & 2,88 & $2,58-3,21$ & 80 & 1,07 & $0,84-1,35$ & 100 \\
\hline 16 & $*>4$ & - & 0 & 1,83 & $1,03-3,25$ & 63,3 \\
\hline 19 & 0,85 & $0,52-1,36$ & 86,6 & 0,04 & $0,02-0,06$ & 100 \\
\hline 20 & 14,81 & $10,17-21,58$ & 20 & 4,72 & $3,73-5,98$ & 40 \\
\hline 21 & $*>16$ & - & 0 & 11,99 & $7,80-18,42$ & 16,6 \\
\hline 22 & 12,03 & $10,51-13,76$ & 13,3 & 4,43 & $3,40-5,49$ & 23,3 \\
\hline 23 & 8,28 & $6,25-10,98$ & 43,3 & 1,14 & $0,88-1,49$ & 100 \\
\hline $\mathrm{CV}$ & $147,51 \%$ & - & $54,75 \%$ & $143,90 \%$ & - & $34,67 \%$ \\
\hline
\end{tabular}

Tabela 2 - Valores de $\mathrm{CL}_{50}$ com os limites de confiança e número de organismos mortos em 4\% do EFLUENTE, seguidos da média e erro padrão da média e coeficiente de variação.

\begin{tabular}{|c|c|c|c|c|c|c|}
\hline \multirow{2}{*}{$\begin{array}{l}\text { Efluente } \\
\text { Coletas }\end{array}$} & \multicolumn{3}{|c|}{24 horas } & \multicolumn{3}{|c|}{48 horas } \\
\hline & $\mathrm{CL}_{50}(\%)$ & Limite de confiança & Mortalidade (\%) & $\mathrm{CL}_{50}(\%)$ & Limite de confiança & Mortalidade (\%) \\
\hline 2 & 4,45 & $3,48-5,70$ & 43,3 & $\star<0,06$ & - & 96,6 \\
\hline 3 & 41,91 & $36,49-48,14$ & 0 & 40,79 & $35,38-47,01$ & 0 \\
\hline 4 & $*>80$ & - & 3,3 & $*>80$ & - & 33,3 \\
\hline 5 & $\star>80$ & - & 0 & $\star>80$ & - & 13,3 \\
\hline 6 & $*>80$ & - & 0 & $*>80$ & - & 6,6 \\
\hline 7 & 17,82 & $15,27-20,79$ & 0 & 6,82 & $6,01-7,44$ & 16,6 \\
\hline 9 & $*>80$ & - & 0 & $*>80$ & - & 3,3 \\
\hline 10 & 10,26 & $6,42-16,37$ & 16,6 & 4,11 & $3,48-4,86$ & 53,3 \\
\hline 13 & $*>80$ & - & 0 & 62,12 & $56,42-68,39$ & 0 \\
\hline 14 & $\star>80$ & - & 3,3 & 79,55 & $71,04-89,09$ & 13,3 \\
\hline 15 & $*>80$ & - & 0 & $*>80$ & - & 0 \\
\hline 16 & 75,66 & $70,01-81,76$ & 0 & 46,66 & $44,75-48,65$ & 0 \\
\hline 19 & $*>80$ & - & 0 & 11,55 & $8,81-15,14$ & 30 \\
\hline 20 & $*>80$ & - & 0 & 78,25 & $73,22-83,64$ & 0 \\
\hline 21 & $\star>80$ & - & 3,3 & 60,54 & $55,86-65,62$ & 6,6 \\
\hline 22 & 39,40 & $35,38-43,57$ & 3,3 & 22,36 & $21,64-23,11$ & 3,3 \\
\hline 23 & 77,49 & $71,92-83,49$ & 0 & 52,09 & $47,76-56,82$ & 0 \\
\hline DP & $\pm 29,71$ & & $\pm 10,8$ & $\pm 27,54$ & & $\pm 25,6$ \\
\hline $\mathrm{CV}$ & $77,9 \%$ & & $251,53 \%$ & $65,16 \%$ & & $156,97 \%$ \\
\hline
\end{tabular}


maiores para o efluente, enquanto que a mortalidade em $4 \%$ foi significativamente menor. $\mathrm{O}$ bom desempenho do reator na redução de toxicidade pode ser facilmente evidenciado ao se comparar os valores obtidos dos ensaios com do afluente e efluente durante os seis meses de operação, tanto de $\mathrm{CL}_{50}$ como mortalidade em 4\% (Tabelas 1 e 2).

\section{Fenóis totais}

Por motivos operacionais, não foi possível fazer a determinação de fenóis totais em todas as amostras. Os valores de fenóis totais do afluente apresentaram grande variação ao longo dos seis meses de coleta. Na Figura 1, no qual é apresentado o valor da concentração de fenóis no afluente e efluente, pode-se observar claramente esta variação. Pela análise do gráfico tornam-se evidentes, também, os baixos níveis de fenóis da água residuária sujeita ao tratamento com relação à saída do reator. Para o afluente, o maior valor obtido foi de 3,3 mg. $\mathrm{L}^{-1}$, enquanto para o efluente foi de apenas $0,62 \mathrm{mg} . \mathrm{L}^{-1}$. Os valores médios obtidos foram de 1,16 $\pm 0,27 \mathrm{mg} \cdot \mathrm{L}^{-1}$ para afluente e $0,22 \pm 0,06 \mathrm{mg} . \mathrm{L}^{-1}$ para efluente $(\mathrm{p}<0.05)$. Em termos percentuais, a remoção média de fenóis totais após a degradação fúngica no reator foi de $78 \%$ com máxima de $98,1 \%$.

\section{Demanda química de oxigênio}

A variação dos valores de DQO encontrados pode ser visualizada no gráfico da Figura 2. Pela análise do gráfico, também tornam-se evidentes os baixos níveis de DQO da água residuária tratada com relação à bruta ao longo de todas as coletas. O nível maior de DQO encontrado no afluente foi de $2179,9 \mathrm{mg} . \mathrm{L}^{-1}$, enquanto para o efluente foi de 711,6 mg.L $\mathrm{L}^{-1}$. Os valores médios obtidos foram 1328,0 $\pm 123,4 \mathrm{mg} . \mathrm{L}^{-1}$ para afluente e $231,2 \pm 41,9 \mathrm{mg} . \mathrm{L}^{-1}$ para efluente $(\mathrm{p}<0.05)$. Foram observadas taxas altíssimas de remoção de DQO por parte do reator, sendo a remoção média de $81 \%$ alcançando um valor máximo de $95,8 \%$.

\section{DISCUSSÃO}

A água residuária oriunda do processo de beneficiamento de castanha de caju revelou um caráter extremamente tóxico uma vez que o afluente do reator apresentou valores de $\mathrm{CL}_{50}$ bastante baixos em todas as coletas tanto em 24 quanto 48 horas de exposição. Esses valores corroboram resultados obtidos por Pimentel et al. (2009) que encontrou $\mathrm{CL}_{50}$ de $1,38 \pm 0,99 \% \mathrm{e}$ $0,60 \pm 0,62 \%$ após 24 e 48 horas de exposição, respectivamente, para a mesma água residuária.

No trabalho realizado por Campos et al.(2002), os efluentes de uma refinaria de petróleo foram testados quanto à toxicidade frente a Artemia salina antes e após serem submetidos a tratamento primário associado a um secundário. Os autores obtiveram $\mathrm{CL}_{50}$ média de $1,2 \%$ para o afluente e nenhuma mortalidade significativa observada para o efluente. No presente estudo não foi possível estimar a $\mathrm{CL}_{50}$ do efluente em várias coletas devido à mesma ter sido maior do que $80 \%$, confirmando o sucesso do tratamento (remoção de toxicidade) assim como no trabalho de anteriormente referido.
Arthaud (2005) avaliou reatores aeróbios inoculados com o fungo Aspergillus niger no que diz respeito à redução de toxicidade de efluentes de uma refinaria de petróleo tendo, também, Artemia sp. como organismo-teste. Durante a pesquisa, o afluente do reator apresentou toxicidade bastante variável com $\mathrm{CL}_{50} 48$ horas média igual a $31,29 \pm 30,20 \%$. A autora afirma que o reator biológico foi eficiente na redução de toxicidade uma vez que em mais de $50 \%$ dos testes foi removida $100 \%$ da toxicidade aguda.

Aggelis et al. (2003) conduziram uma avaliação da toxicidade dos efluentes do processamento da oliva antes e após tratamento com o fungo Pleurotus ostreatus, utilizando Artemia sp. e obtiveram diminuição da toxicidade após o tratamento com aumento da $\mathrm{CL}_{50} \mathrm{em} 24$ horas que passou de $4,5 \%$ no efluente não tratado para $12,5 \%$.

Apesar da sensibilidade do gênero Artemia ser bastante variável quando submetida a diferentes tipos de águas residuárias (Guerra, 2001; Campos et al., 2002; Aggelis et al., 2003; Svensson et al., 2005; Souza et al., 2007; Santana \& Machado, 2008; Pimentel et al., 2009), esse organismo ainda é muito utilizado e recomendado em testes de toxicidade. Costa et al. (2008) chamam atenção para facilidades conquistadas quando se elege Artemia sp. como organismo-teste: os cistos são facilmente adquiridos em qualquer loja especializada em artigos de aquários (o que torna os testes mais sustentáveis) e resistem à secagem quando estocados por longos períodos. $\mathrm{O}$ baixo custo e as facilidades envolvidas na realização do teste de toxicidade aguda com Artemia sp. são bons motivos para que

Fenóis totais

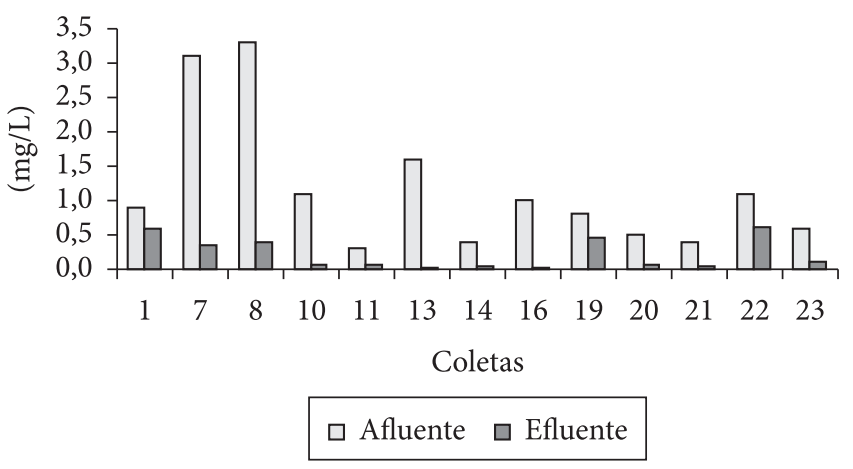

Figura 1 - Distribuição dos valores de fenóis totais das amostras do Afluente e Efluente em 13 das 23 coletas realizadas.

DQO

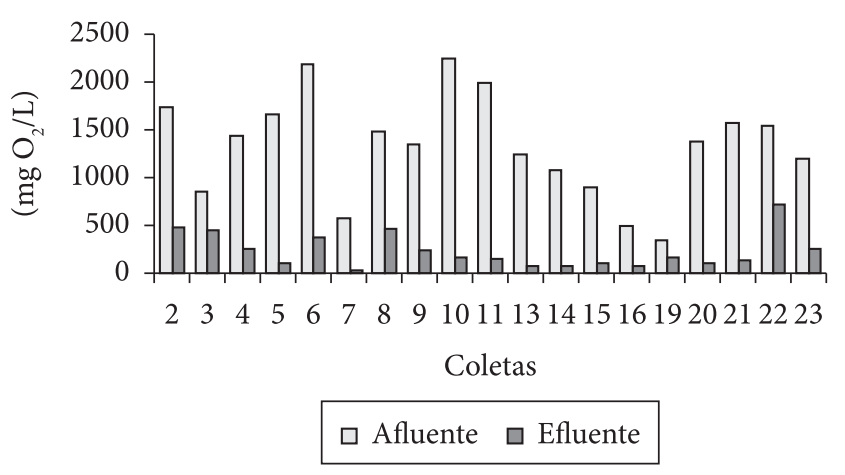

Figura 2 - Distribuição dos valores de DQO das amostras do Afluente e Efluente em 19 das 23 coletas realizadas. 
a implementação do teste como forma de monitoramento na própria indústria seja encorajada. $\mathrm{O}$ teste de toxicidade aguda com Artemia sp. é ideal tanto quando se pretende monitorar um sistema completo de tratamento quanto para avaliar a eficiência de etapas em separado deste tratamento por meio da observação do aumento ou diminuição da toxicidade.

A remoção de fenóis totais da água residuária da indústria de beneficiamento de castanha de caju desempenhada pelos os fungos do reator biológico foi bastante satisfatória. Sampaio et al. (2004) ressaltam que as cargas orgânicas do efluente da indústria da castanha podem variar bastante de acordo com a atividade desempenhada: o beneficiamento propriamente dito, ou os processos de lavagem. Além destes, as chuvas também podem modificar a concentração de compostos da mistura. É importante que se diga que apesar desta variação, não houve uma semana sequer em que os fungos do reator não tenham sido capazes de reduzi-las a níveis seguros com porcentagens de remoção chegando a quase $100 \%$.

Segundo Guerra (2001), para que a carga prejudicial de compostos fenólicos lançados ao ambiente seja reduzida, os esforços devem ser focalizados na redução da toxicidade, fazendo com que esta descarga seja menos prejudicial. A legislação vigente para lançamento de efluentes industriais em ambientes aquáticos (Resolução CONAMA 397/2008) estabelece uma concentração máxima permitida de $0,5 \mathrm{mg} . \mathrm{L}^{-1}$ de fenóis totais (CONAMA, 2008).

No que diz respeito à Demanda Química de Oxigênio (DQO), os resultados concernentes ao afluente não apresentaram variação tão acentuada quanto os de fenóis. O tratamento empregado aos resíduos líquidos do beneficiamento da castanha foi bastante satisfatório também no tocante à redução de DQO. No total foram realizadas 19 determinações e em todas elas houve redução aguda dos valores no efluente em comparação ao afluente. Desta forma, o reator biológico utilizado nesta pesquisa foi, de fato, capaz de baixar bruscamente os níveis de matéria orgânica do afluente atingindo um valor máximo de $95,8 \%$ de remoção de DQO.

Em um dos raríssimos trabalhos de caracterização da água residuária da indústria de beneficiamento de castanha de caju disponíveis, Silva et al. (2006) encontraram valores de DQO no efluente bruto de $1921 \mathrm{mg} . \mathrm{L}^{-1} \mathrm{em}$ uma indústria e $1535 \mathrm{mg} . \mathrm{L}^{-1} \mathrm{em}$ outra, ambas localizadas no município de Fortaleza. Estes resultados corroboram os valores encontrados no presente trabalho cuja média de DQO obtida foi de $1328 \pm$ $123,4 \mathrm{mg} . \mathrm{L}^{-1}$. Os autores submeteram o efluente a tratamento fúngico em quatro experimentos diferentes, tendo obtido as seguintes médias de remoção de DQO: $77,73,71$ e $65 \%$. Desta forma, os autores concluíram que o uso de fungos decompositores é adequado para tratamento de efluentes da indústria de beneficiamento da castanha de caju.

Foi encontrada correlação positiva significativa tanto entre a toxicidade e a concentração de fenóis, quanto entre a toxicidade e a DQO. É importante e recomendado que os testes ecotoxicológicos sejam integrados às análises químicas. Para que a qualidade de qualquer tipo de água (residuária ou não) seja definida, análises baseadas em critérios físico-químicos e biológicos são indispensáveis e complementares (Villegas-
Navarro et al., 1999). O aumento da toxicidade aliado ao aumento do teor fenólico é um comportamento de certa forma já esperado, pois sabe-se da grande toxicidade associada aos fenóis. (Varghese et al., 1986; Autenrieth et al., 1991; Martirani et al., 1996; George \& Kuttan, 1997; Khatami et al., 1998; Daví \& Gnudi, 1999; Au et al., 2003; Newman \& Unger, 2003; Veeresh et al., 2005; Trevisan et al., 2006; Façanha et al., 2007; Stasiuk et al., 2008; Stasiuk \& Kozubek, 2008; Pimentel et al., 2009). A correlação positiva entre toxicidade e DQO sugere que $\mathrm{o}(\mathrm{s})$ causador(es) da toxicidade sofrida pelo organismo-teste seja(m) de natureza orgânica, como os fenóis.

Os efeitos tóxicos causados por efluentes complexos podem ocorrer por meio de uma ação sinergética entre seus componentes sem que seja possível a detecção deste efeito por nenhum dos parâmetros determinados individualmente. Entretanto, análises não-ecotoxicológicas podem responder a algumas questões e seguem sendo indispensáveis. Sponza (2003) destaca que todo efluente que apresenta toxicidade aguda deveria ser caracterizado tão completamente quanto possível por análises físicas e químicas.

O beneficiamento da castanha de caju consiste hoje numa das mais intensas atividades produtivas em toda a Região Nordeste com a marcante presença de indústrias de grande porte. Estas indústrias são geradoras de grandes quantidades de resíduos líquidos que, até bem pouco tempo, jamais haviam sido pesquisados. Os estudos de caracterização deste efluente são ainda bastante incipientes e, por isso, qualquer nova abordagem e descoberta são extremamente relevantes. Sabe-se, até o momento, que tal efluente é potencialmente poluidor, apresentando em sua composição uma série de compostos fenólicos reconhecidamente tóxicos. Uma caracterização ecotoxicológica preliminar (Pimentel et al., 2009) evidenciou a forte toxicidade destes efluentes mesmo depois de fluírem pela estação de tratamento da indústria. Tais resultados serviram como um alerta para a necessidade de se aprimorem técnicas no sentido de tratá-lo adequadamente, reduzindo esta toxicidade, a fim de minimizar os impactos de seu lançamento nos cursos d'água.

Tendo em vista que as indústrias precisam cumprir os critérios de qualidade de efluentes estabelecidos na Resolução CONAMA 357 (que inclui os testes de toxicidade como parâmetro), é importante que se desenvolvam ensaios simples e sustentáveis (uma vez que os cistos de Artemia sp. são comercializados) para que monitoramentos nos tratamentos de resíduos líquidos sejam implementados definitivamente nestas empresas. Sendo assim, Artemia sp. mostra-se como um dos organismos mais promissores para este fins pelos seguintes aspectos: 1) pela facilidade de obtenção; 2) ciclo de vida bem conhecido; 3 ) ensaio rápido e de baixíssimo custo; e 4) respostas satisfatórias em testes para verificação da eficiência de tratamentos de efluentes fenólicos.

$\mathrm{O}$ tratamento com fungos realizado no presente trabalho foi satisfatório na redução de DQO, concentração de compostos fenólicos e da toxicidade associada, sendo o ensaio agudo com Artemia sp. bastante adequado para este tipo de efluente. 
Agradecimentos - Os autores agradecem à Fundação Cearense de Apoio à Pesquisa (FUNCAP) pelo suporte financeiro; ao Prof. Freire (EMBRAPA-CE) pelo isolamento dos fungos utilizados neste trabalho. Gratos também a Wilson Franklin Júnior e Davi Andrade pela preciosa colaboração na logística.

\section{REFERÊNCIAS BIBLIOGRÁFICAS}

AGGELIS, G., ICONOMOU, D., CHRISTOU, M., BOKAS, D., KOTZAiliaS, S., CHRISTOU, Z., TSAGOU, V. \& PAPANIKOLAOU, S., 2003, Phenolic removal in a model olive oil mill wastewater using Pleurotus ostreatus in a bioreactor cultures and biological evaluation of the process. Water Res, 37:3897-3904. doi: 10.1016/S0043-1354(03)00313-0.

AIT-AISSA, S., PANDARD, P., MAGAUD, H., ARRIGO, A. P., THYBAUD, E. \& PORCHER, J. M., 2003, Evaluation of an in vitro hsp70 induction test for toxicity assessment of complex mixtures: comparison with chemical analyses and ecotoxicity tests. Ecotox Environ. Safe, 54:92-104. doi:10.1016/S01476513(02)00026-X.

APHA, American Public Health Association, AWWA - American Water Works Association \& WPCF, Water Environment Federation, 2005, Standard methods for the examination of water and wastewater. $21^{\text {nd }}$. ed. APHA, AWWA \& WEF, Washington, D.C., 1085p.

ARTHAUD, I. D. B., 2005, Redução de toxicidade do efluente de uma refinaria de petróleo, empregando reatores biológicos aeróbios, de leito fixo e fluxo contínuo ascendente, inoculados com Aspergillus niger. Dissertação (Mestrado em Engenharia Civil)-Universidade Federal do Ceara, Fortaleza, 71p.

AU, D. W. T., YURCHENKO, O. V. \& REUNOV, A. A., 2003, Sublethal effects of phenol on spermatogenesis in sea urchins (Anthocidaris crassipina). Environ Res, 93:92-98. doi: 10.1016/ S0013-9351(02)00094-4.

AUTENRIETH, R. L., BONNER, J. S., AKGERMAN, A., OKAYGUN, M. \& McCREARY, E. M., 1991, Biodegradation of phenolic wastes. J. Hazard. Mater, 28:29-53. doi: 10.1016/03043894(91)87004-L.

CAMPOS, J. C., BORGES, R. M. H., OLIVEIRA FILHO, A. M., NÓBREGA, R. \& SANT'ANNA Jr., G. L., 2002, Oilfield wastewater treatment by combined microfiltration and biological processes. Water Res., 36:95-104. doi:10.1016/S00431354(01)00203-2.

CETESB, Companhia Ambiental do Estado de São Paulo, 1987, Água do Mar: teste de toxicidade aguda com Artemia. São Paulo, SP. L05.021/1987.

CONAMA, Conselho Nacional do Meio Ambiente, 2005, Resolução $\mathrm{n}^{\mathrm{o}}$ 357, de 17 de março de 2005. Diário Oficial da União, Brasília, DF, Seção 1, p.58-63. Available from: <http//: www.mma.gov.br/ port/conama/res/res05/res35705.pdf>.

CONAMA, Conselho Nacional do Meio Ambiente, 2008, Resolução $n^{\circ}$ 397, de 03 de abril de 2008. Diário Oficial da União, Brasília, DF, Seção 1, p.58-63. Available from: <http:// www.mma.gov.br/ port/conama/legiabre.cfm?codlegi $=563>$.

COSTA, C. R.; OLIVI, P.; BOTTA, C. M. R. \& ESPINDOLA, E. L. G., 2008, A toxicidade em ambientes aquáticos: discussão e métodos de avaliação. Quim Nova, 7:1820-1830.

DAVÍ, M. L. \& GNUDI, F., 1999, Phenolic compounds in surface water. Water Res., 33:3213-3219. doi:10.1016/S00431354(99)00027-5.

FAÇANHA, M. A., MAZZETO, S. A., CARIOCA, J. O. \& BARROS, G. G, 2007, Evaluation of antioxidant properties of a phosphorated cardanol compound on mineral oils (NH10 and NH20). Fuel, 86:2416-2421. doi: 10.1016/j.fuel.2007.01.034.

GEORGE, J. \& KUTTAN, R., 1997, Mutagenic, carcinogenic and cocarcinogenic activity of cashewnut shell liquid. Cancer Let., 112:1-16. doi:10.1016/S0304-3835(96)04540-5.

GUERRA, R., 2001, Ecotoxicological and chemical evaluation of phenolic compounds in industrial effluents. Chemosphere, 44:1737-1747. doi:10.1016/S0045-6535(00)00562-2.

HAMILTON, M. A.; RUSSO, R. C. \& THURSTON, R. V., 1977, Trimmed Spearman-Karber method for estimating median lethal concentrations in toxicity bioassays. Environ. Sci. Technol., 11:714-719. doi: 10.1021/es60130a004.

HUWANG, S. C.; LIN, C. S.; CHEN, I. M.; CHEN, J. M.; LIU, L. Y. \& DODDS, L. K., 2004, Removal of multiple nitrogenous wastes by Aspergillus niger in a continuous fixed-slab reactor. Bioresource Technol., 93:131-138. doi: 10.1016/j.biortech.2003.10.017.

JOU, C. J. G. \& HUANG, G. C., 2003, A pilot study for oil refinery wastewater treatment using a fixedfilm Bioreactor. Adv. Environ. Res., 7:463-469. doi:10.1016/S1093-0191(02)00016-3.

KHATAMI, S. H., PASCOE, D. \& LEARNER, M. A., 1998, The acute toxicity of phenol and unionized ammonia, separately and together, to the ephemeropteran Baetis rhodani (Pictet). Environ. Pollut., 99:379-387. doi:10.1016/S0269-7491(98)00003-7.

LORENZI, H. \& MATOS, F. J. A., 2002, Plantas medicinais no Brasil: nativas e exóticas cultivadas. Instituto Plantarum, Nova Odessa, SP, 544p.

MARTIRANI, L., GIARDINA, P., MARZULLO, L. \& SANNIA, G., 1996, Reduction of phenol content and toxicity in olive oil mill waste waters with the ligninolytic fungus Pleurotus Ostreatus. Water Res., 30:1914-1918. doi:10.1016/0043-1354(95)00330-4.

NEWMAN, M. C. \& UNGER, M. A., 2003, Fundamentals of ecotoxicology. $2^{\text {nd }}$ ed. Lewis Publishers, New York, 458p.

PIMENTEL, M. F. P.; LIMA, D. P.; MARTINS, L. B.; BEATRIZ, A.; SANTAELlA, S. T. \& COSTA-LOTUFO, L. V., 2009, Ecotoxicological analysis of cashew nut industry effluents, specifically two of its major phenolic components, cardol and cardanol. PANAMJAS, 4:363-368.

SAMPAIO, G. M. M. S.; SANTOS, E. M. A.; LEITÃO, R. C.; FACÓ, A. M.; MENEZES, E. A. \& SANTAELLA, S. T., 2004, Pós-tratamento de efluente de um reator UASB através de um reator biológico com fungos. Eng. Sanit. Ambient., 1:73-81.

SANTANA, V. S. \& MACHADO, N. R. C. F., 2008, Photocatalytic degradation of the vinasse under solar radiation. Catal. Today, 133:606-610. doi:10.1016/j.cattod.2007.12.131.

SANTAELLA, S. T., 1999, Estudos de tecnologias apropriadas para tratamento de efluentes da indústria de castanha de caju. Relatório Institucional de Pesquisa. Departamento de Engenharia Hidráulica e Ambiental - UFC. Fortaleza.

SILVA, F. J. A.; SALES, M. E. C.; ESCOUTO, F. M. B.; ANDRADE, M. I. R.; SANTAELLA, S. T., 2006, Degradação de efluente de indústria de castanha de caju por fungos decompositores em reator de fluxo contínuo - DQO e sistema carbônico. $23^{\circ}$ Congresso Brasileiro de Engenharia Sanitária e Ambiental. Campo Grande.

SOARES, J. B., 1986, O caju: aspectos tecnológicos. Banco do Nordeste, Fortaleza, 254p.

SOUSA, E. C. P. M., 2002, Toxicologia marinha: histórico. In: I. A. Nascimento, E. C. P. M. Sousa \& M. Nipper (Ed.). Métodos em ecotoxicologia marinha. Aplicações no Brasil. Artes Gráficas e Indústria, São Paulo, p.9-12. 
SOUZA, S. M. A. G. U.; FORGIARINI, E. \& SOUZA, A. A. U, 2007, Toxicity of textile dyes and their degradation by the enzyme horseradish peroxidase (HRP). J. Hazard. Mater., 147:10731078. doi:10.1016/j.jhazmat.2007.06.003.

SPONZA, D. T., 2003, Application of toxicity tests into discharges of the pulp-paper industry in Turkey, Ecotox. Environ. Safe., 54:74-86. doi:10.1016/S0147-6513(02)00024-6.

STASIUK, M. \& KOZUBEK, A., 2008, Membrane perturbing properties of natural phenolic and resorcinolic lipids. FEBS Lett., 582:3607-3613. doi:10.1016/j.febslet.2008.09.039.

STASIUK, M., BARTOSIEWICZ, D. \& KOZUBEK, A., 2008, Inhibitory effect of some natural and semisynthetic phenolic lipids upon acetylcholinesterase activity. Food Chem, 108:9961001. doi:10.1016/j.foodchem.2007.12.011.

SVENSSON, B. M., MATHIASSON, L., MARTENSSON, L. \& BERGSTROM, S., 2005, Artemia salina as test organism for assessment of acute toxicity of leachatewater from landfills. Environ. Monit. Assess., 102:309-321. doi: 10.1007/s10661-005-6029-z.

TREVISAN, M. T. S., PFUNDSTEIN, B., HAUBNER, R., WURTELE, G., SPIEGEDHALDER, B., BARTSCH, H. \& OWEN, R. W., 2006, Characterization of alkyl phenols in cashew
(Anacardium occidentale) products and assay of their antioxidant capacity. Food Chem. Toxicol., 44:188-197. doi:10.1016/j. fct.2005.06.012.

VARGHESE, I., RAJENDRAN, R., SUGATHAN, C. K. \& VIJAYAKUMAR, T., 1986, Prevalence of oral submucous fibrosis among the cashew workers of Kerala-South India. Indian J. Cancer, 23:101-104.

VEERESH, G. S., KUMAR, P. \& MEHROTA, I., 2005, Treatment of phenol and cresols in upflowanaerobic sludge blanket (UASB) process: a review. Water Res., 39:154-170. doi:10.1016/j. watres.2004.07.028.

VEIGA, L. F. \& VITAL, N., 2002, Teste de toxicidade aguda com o microcrustáceo Artemia sp. In: I. A. Nascimento, E. C. P. M., Sousa \& M. Nipper (ed.), Métodos em ecotoxicologia marinha. Aplicações no Brasil. Artes Gráficas e Indústria, São Paulo, p.111-122.

VILLEGAS-NAVARRO, A., GONZHLEZ, M. C. R., LOPEZ, E. R., AGUILAR, R. D. \& MARGAL, W. S., 1999, Evaluation of Daphnia magna as an indicator of toxicity and treatment efficacy of textile wastewaters. Environment Int., 5:619-624. doi:10.1016/ S0160-4120(99)00034-3. 